\title{
IDENTIFIKASI UCAPAN WARNA MENGGUNAKAN LPC (LINIER PREDICTIVE CODE ) DAN KELOMPOK PEMILIHAN BOBOT
}

\author{
Heriyanto, Oliver Samuel Simanjuntak \\ Jurusan Teknik Informatika, UPN "Veteran" Yogyakarta \\ Jl. Babarsari 2 Tambakbayan 55281 Telp (0274) 485323 \\ 1)e-mail : mr_heriyanto_skom@yahoo.com \\ 2)e-mail: oliversimanjuntak@yahoo.com
}

\begin{abstract}
Color recognition lessons can be done by viewing pictures and speaking in a voice. Introduction with voice detection to recognize colors for children is necessary both with sound and image media. In children learning to know the color can be done by using the introduction of color speech. When learning to recognize color with speech then do the sound detection or color greeting using LPC. One method to recognize with LPC (Linear Predictive Code) can improve 60\% accuracy. Characteristic extraction in addition to using Linear Predictive Coding (LPC) method based on Aibinu et al. (2011) with LPC between $40 \%-60 \%$. This research uses LPC which produce coefficient of cepstral which then is done by fiture selection. Combination of selection fiture taken among others by 1 . Grouping the value of data 2. Doing weight selection. The results of test accuracy conducted by 1.10 color speech performed on men and women as many as 10 people get a percentage of $95 \%$.
\end{abstract}

Keywords: color, speech, LPC, study, identification

Abstrak
Pelajaran mengenal warna dapat dilakukan dengan melihat gambar dan mengucapkan
dengan suara. Pengenalan dengan deteksi suara untuk mengenal warna-warna bagi anak-
anak sangat diperlukan baik dengan media suara maupun gambar. Pada anak-anak belajar
mengenal warna dapat dilakukan dengan menggunakan pengenalan ucapakan warna.
Pada saat belajar mengenal warna dengan ucapan maka dilakukan deteksi suara atau
ucapan warna menggunakan LPC. Salah satu metode untuk mengenal ucapakan dengan
LPC (Linier Predictive Code) dapat meningkatkan akurasi $60 \%$. Ekstraksi ciri selain
menggunakan metode Linear Predictive Coding (LPC) berdasarkan Aibinu dkk. (2011)
dengan LPC diantara 40\%-60\%. Penelitian in menggunakan LPC yang menghasilkan
kooefisien cepstral yang kemudian dilakukan seleksi fiture. Kombinasi seleksi fiture yang
diambil diantaranva dennan 1 Mennelnmnnkan nilai data ? Melakıkan nemilihan hnhnt

\section{PENDAHULUAN}

Pelajaran disekolah untuk anak-anak diantaranya mengenal warna. Pengenalan warna dapat dilakukan dengan belajar melihat warna tersebut dan juga dapat dilakukan dengan pengenalan ucapana warna tersebut. Ucapan anak-anak yang dilafalkan kemudian menghasilkan tampilan warna di depan layar computer dapat memicu belajar warna secara interactive. Pendekatan metode yang dilakukan diantaranya dengan LPC (Linier Predictive Code) cukup baik untuk mengenal ucapan speech recognition maupun speaker recognition akurasi mencapai 40\%$60 \%$. Hal tersebut dapat dilakukan kombinasi dengan kelompok pemilihan bobot agar dapat menjadi lebih optimal. 


\section{TINJAUAN PUSTAKA}

a. Penelitian Chenghui Yang et al. (2012) melakukan penelitian pada bahasa di Nigeria menyebutkan angka 1 sampai 9 baik speaker laki-laki maupun wanita, deteksi pengenalan suara pada kata dengan LPC juga dilakukan. Penelitian lain LPC Jon Gudnason et al. (2008) melakukan penelitian dengan LPC.

b. Transformasi Fourier Cepat FFT (Fast Fourier Transform) mengubah masing-masing N sampel dari domain waktu menjadi dosmain frekuensi. FFT adalah algoritma cepat untuk mengimplementasikan discrete fourier transform (DFT) dengan didefinisikan pada kumpulan (set) $\mathrm{N}$ sampel. Sinyal suara tersebut akan diubah ke dalam domain frekuensi dengan menggunakan Fast Fourier Transform (FFT) sehingga akan di dapatkan sinyal suara yang terpetakan dalam dalam spectrum frekuensi.

c. Suatu metode yang umum untuk ekstraksi fitur sinyal ucapan dengan MFCC dan LPC peneliti menggunakan metode LPC (Linier Predictive Code), digunakan untuk ucapan warna.

\section{METODE PENELITIAN}

a. Studi Literatur. Penulis mencari sumber pustaka atau dokumen untuk mempelajari permasalahan seperti teori Audio, sehingga penulis memahami konsep Voice Recognition.

b. Analisa. Menggunakan analysis LPC dan mengkombinasikan kelompok pemilihan bobot

c. Metodologi rekayasa perangkat lunak yang digunakan model air terjun (waterfall model). Metode ini mempunyai pendekatan sekuensial yang sistematis yang meliputi Silberschatz, Korth et al. (2011).

- Rekayasa dan pemodelan sistem

- Analisis kebutuhan perangkat lunak

- Perancangan (desain)

- Penulisan program (coding)

- Pengujian (testing)

- Pemeliharaan (maintenance)

\section{HASIL DAN PEMBAHASAN}

Identifikasi ucapan warna dilakukan proses pengambilan sample wave. Frekwensi yang diambil $44.100 \mathrm{kHz}$ Stereo 16 bit. Input ucapan warna yang diambil yaitu warna 1.Merah, 2. Jingga, 3.Kuning, 4.Hijau, 5.Biru, 6.Nila, 7.Ungu, 8.Coklat, 9.Hitam dan 10.Putih. Pengambilan sample suara terdiri dari Laki-laki dan Perempuan berusia 5-20 tahun.

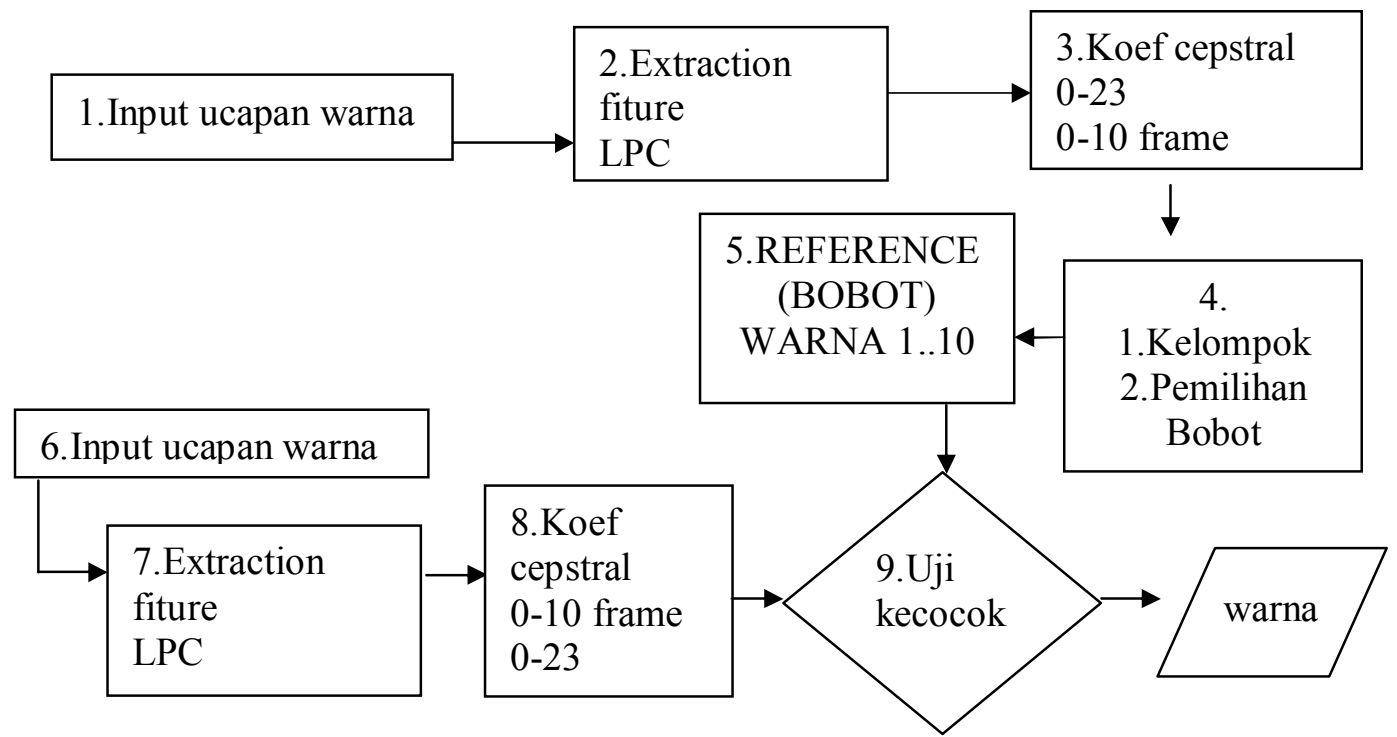

Gambar 1. Bagan sistem identifikasi ucapan warna 
Proses pengambilan data suara dilakukan dengan merekam seperti pada Gambar 2 dibawah ini.

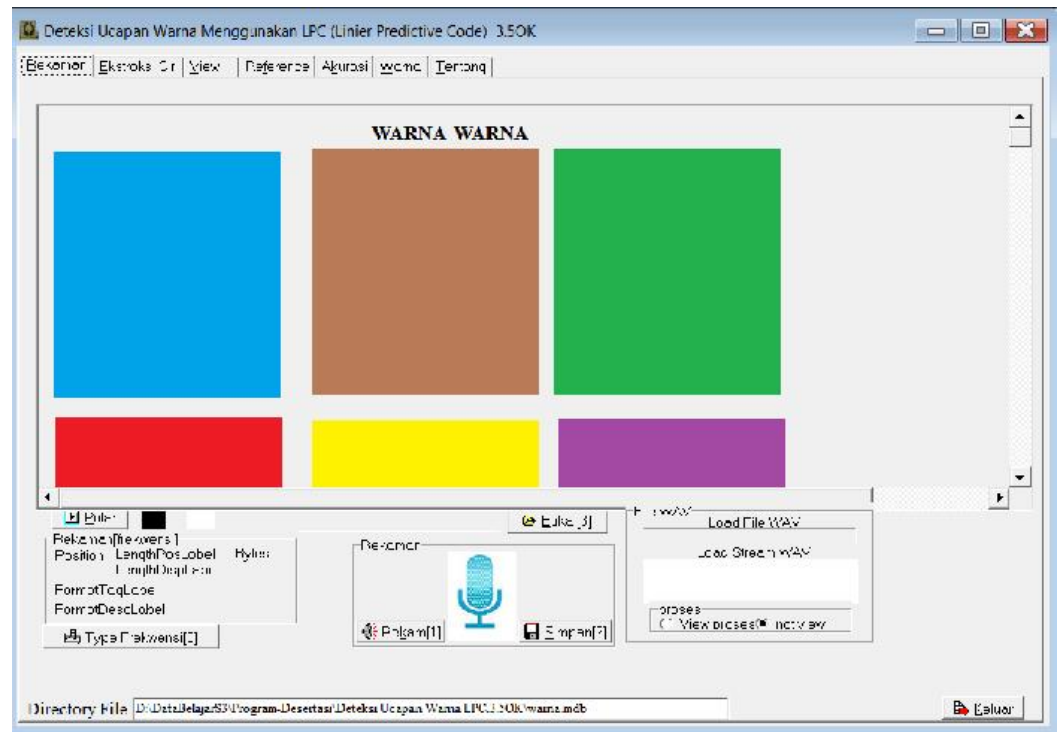

Gambar 2. Rekaman ucapan warna

Pada proses kedua dilakukan ekstraksi ciri dengan metode LPC (Linier Predictive Code). Data yang dihasilkan berupa koefisien cepstral yang terdiri dari 0-23 koefisien cepstral dan 0-10 frame. Hasil ekstraksi ciri dapat dilihat pada Gambar 3.

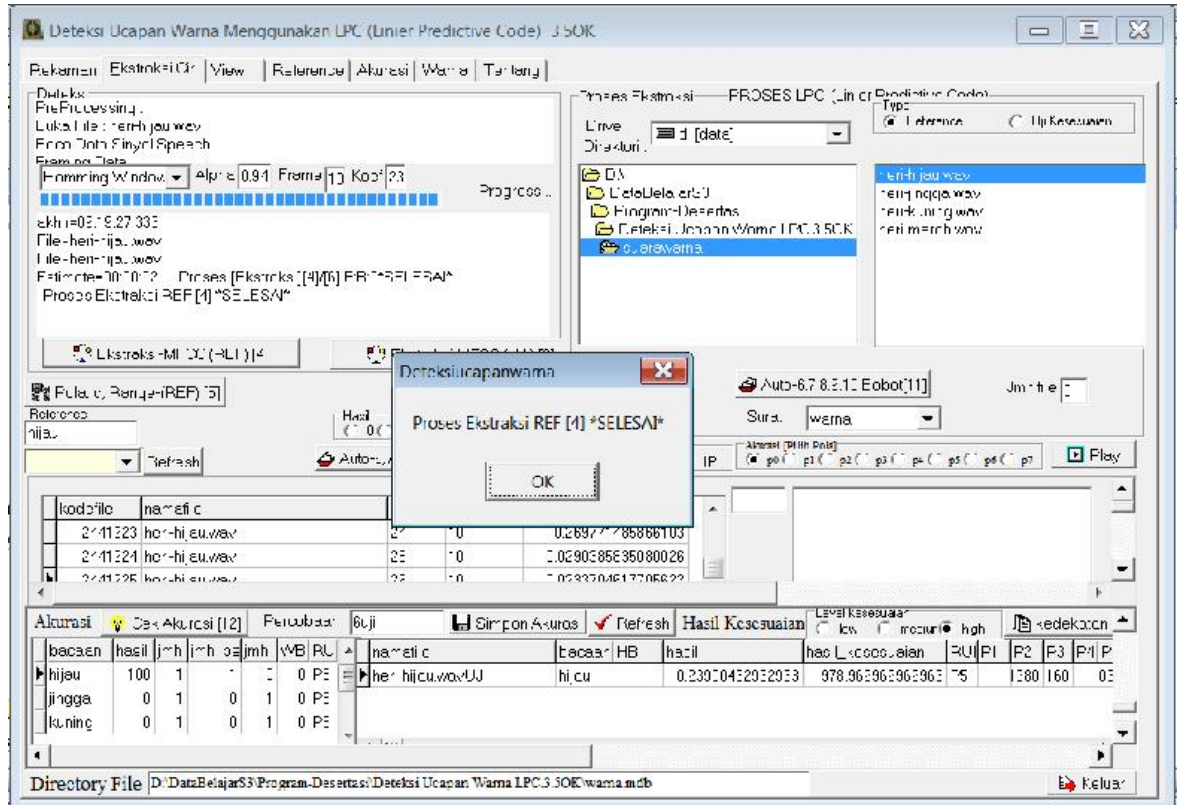

Gambar 3. Proses Ekstraksi Ciri 
Pada proses selanjutnya setelah didapat koefisien cepstral maka dilakukan pengelompokan nilai dari masing-masing cepstral yang menghasilkan kelas p1..p2...p7 seperti di bawah ini. Pada pengelompokan kelas dipilih dilakukan pemilihan bobot yang tersebar dari masing-masing frame dipilih bobot yang unggul.

\begin{tabular}{|c|c|c|c|c|c|c|c|c|c|c|c|c|c|c|c|c|c|c|}
\hline & kade & fra & bacaar & Warna & PS & pola $\mathrm{P}$ & & $\mathrm{P} 2$ & P3 & P4 & P5 & P6 & $P 7$ & pola. & PF2 & PF3 & PF5 & PF6 \\
\hline B & 7072 & 0 & hijau & (BLOB) & 1 & REF & 1 & 4 & 3 & 12 & 3 & 3 & 0 & REF & 0 & 0 & 0 & 0 \\
\hline & 7073 & 1 & hijau & (BLOB) & 1 & REF & 0 & 11 & 9 & 12 & 8 & 6 & 0 & REF & 11 & 9 & 8 & 6 \\
\hline & 7084 & 2 & hijau & (BLOB) & 1 & REF & 0 & 12 & 11 & 12 & 11 & 11 & 0 & REFF & 0 & 0 & 0 & 0 \\
\hline & 7092 & 3 & hijau & (BLOB) & 1 & REF & 0 & 11 & 11 & 12 & 11 & 10 & 0 & REEF & 11 & 0 & 0 & 0 \\
\hline & 7093 & 4 & hijau & (BLOB) & 1 & R.EF & 0 & 11 & 11 & 12 & 11 & 11 & 0 & REF & 0 & 11 & 11 & 0 \\
\hline & 7094 & 5 & hijau & (BLOB) & 1 & REF & 0 & 11 & 11 & 12 & 11 & 11 & 0 & REF & 11 & 0 & 11 & 11 \\
\hline & 7095 & 6 & hijau & (BLOB) & 1 & REEF & 0 & 12 & 11 & 12 & 11 & 11 & 0 & REEF & 0 & 11 & 0 & 11 \\
\hline & 7096 & 7 & hijau & (BLOB) & 1 & REF & 0 & 12 & 11 & 12 & 11 & 11 & 0 & REF & 0 & 0 & 11 & 11 \\
\hline & 7097 & 8 & hijau & (BLOB) & 1 & REF & 0 & 12 & 11 & 12 & 11 & 11 & 0 & REF & 0 & 11 & 0 & 0 \\
\hline & 7098 & 9 & hijau & (BLOB) & 1 & REF & 0 & 11 & 11 & 12 & 11 & 11 & 0 & REF & 11 & 11 & 11 & 11 \\
\hline & 7074 & 10 & hijau & $(\mathrm{BLOB})$ & 1 & REF & 1 & 12 & 11 & 12 & 11 & 9 & 0 & REF & 0 & 11 & 11 & 0 \\
\hline
\end{tabular}

\section{Gambar 4. Reference Suara}

Hasil referensi suara dari P1..P7 setelah dilakukan pemilihan menjadi PF2...PF6 seperti pada Gambar 4. Proses selanjutnya dilakukan uji coba dengan melakukan penghitungan data yang tersebut di lakukan perkalian sequensial terhadap bobot yang sudah dipilih (PF2...PF6).

Pengujian dilakukan dengan menguji dari hasil ekstraksi ciri seperti pada Gambar 5.

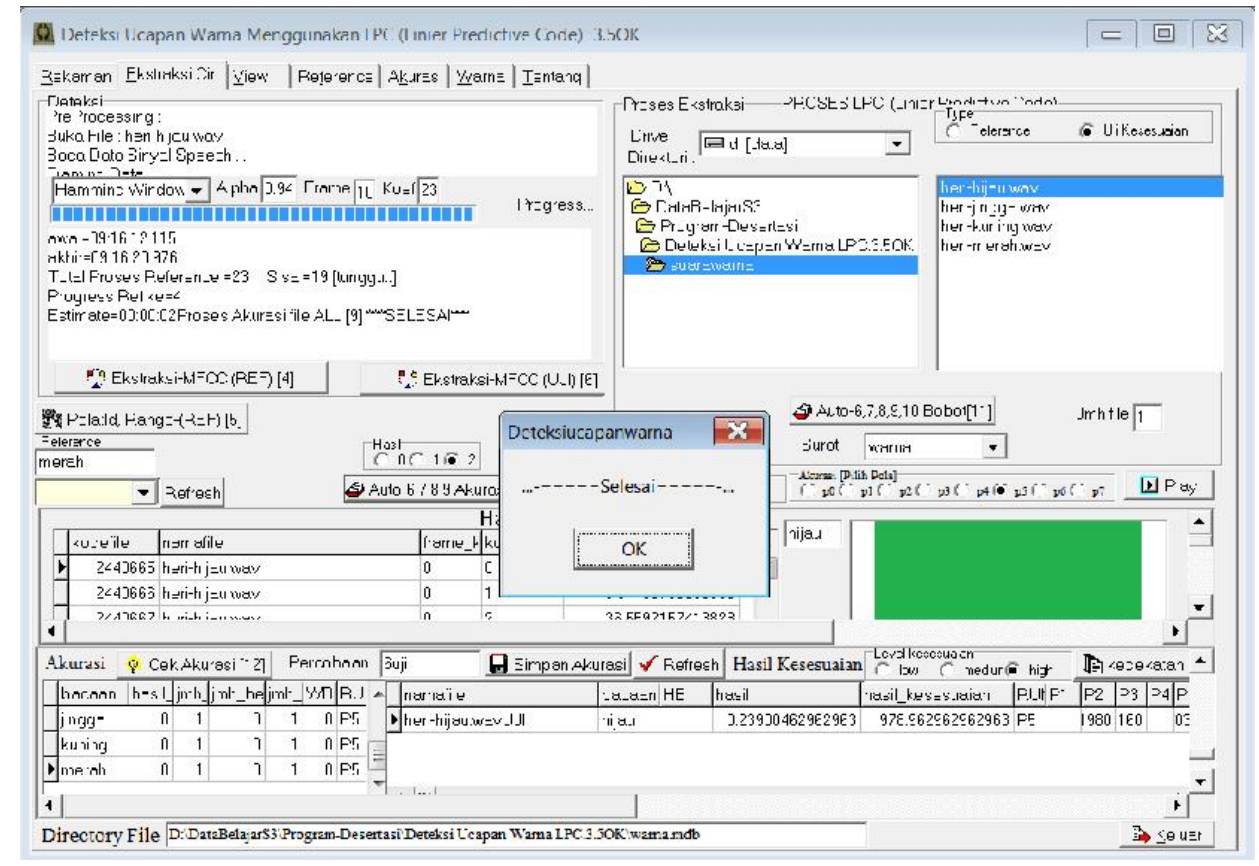

Gambar 5. Pengujian Ucapan Warna

Pengujian dilakukan terhadap seluruh warna 1.. 10 dilakukan berbagai uji coba file mulai 2-10 file dengan Laki-laki dan perempuan bervariasi mulai 4-10 dengan data hasil akurasi rata-rata 95\% dapat dilihat pada Tabel 1 di bawah : 
Tabel 1. tabel hasil percobaan

\begin{tabular}{|l|l|l|l|c|c|}
\hline \multicolumn{1}{|c|}{ Warna } & File & L & P & Jumlah Orang & Hasil Akurasi \\
\hline Merah & 6 & 3 & 3 & 6 & 100 \\
\hline Jingga & 8 & 4 & 4 & 8 & 90 \\
\hline Kuning & 7 & 4 & 3 & 7 & 100 \\
\hline Hijau & 10 & 5 & 5 & 10 & 90 \\
\hline Biru & 10 & 3 & 3 & 6 & 80 \\
\hline Nila & 7 & 3 & 4 & 7 & 100 \\
\hline Ungu & 4 & 2 & 2 & 4 & 100 \\
\hline Hitam & 3 & 3 & 2 & 5 & 90 \\
\hline Putih & 5 & 2 & 2 & 4 & 100 \\
\hline Coklat & 2 & 4 & 5 & 9 & 100 \\
\hline & & & \multicolumn{5}{|c|}{ Rata-rata } \\
\hline
\end{tabular}

\section{KESIMPULAN}

Hasil penelitian dengan menggunakan LPC yang didapat kooefisien cepstral yang kemudian dilakukan seleksi fiture. Kombinasi seleksi fiture yang diambil diantaranya dengan 1. Mengelompokan nilai data 2. Melakukan pemilihan bobot. Hasil akurasi uji coba dilakukan dengan ucapan 1..10 warna dilakukan terhadap laki-laki dan perempuan sebanyak 10 orang. Pengenalan ucapan warna setelah didapat ekstraksi ciri dengan LPC kemudian dilakukan kombinasi koef cepstral dan frame. Pendeteksian bacaan ucapan warna melalui voice recognition dengan metode LPC dan kelompok pemlilihan bobot dengan didapat akurasi sebesar $95 \%$.

\section{DAFTAR PUSTAKA}

Adipranata, R. dan Resmana, 1999, Pengenalan Suara Manusia Dengan Metode LPC Dan Jaringan Saraf Tiruan Propagasi Balik Prosiding Seminar Nasional I Kecerdasan Komputasional Universitas Indonesia, 20-21 Juli 1999, 99-033, Hal 1-5

Aibinu, A.M., Salami, M.J.E., Najeeb, A.R., Azeez, J. F. dan Rajin, S.M.A.K., 2011, Evaluating The Effect Of Voice Activity Detection In Isolated Yoruba Word Recognition System 2011 4th International Conference On Mechatronics (ICOM), 17-19 May 2011, Kuala Lumpur, Malaysia 978-1-61284-437-4/11/\$26.00 @2011 IEEE. Hal 1-5

Botros, N., Deiri, M.Z. dan Hsu, P.,1990, Automatic Voice Recognition Using Artificial Neural Network Approach 89ch2785-4/90/0000-0763\$01.00 1990 IEEE, Hal 762-765

Chen, X., Huang, J., Wang, Y. dan Tao, C.,2012, Incremental Feedback Learning Methods For Voice Recognition Based On DTW Proceedings of 2012 International Conference on Modelling, Identification and Control, Wuhan, China, June 24-26, 2012, Hal 1011-1016

Gudnason, J. dan Brookes, M., 2008, Voice Source Cepstrum Coefficients For Speaker Identification, ICASSP 2008, 1-4244-1484-9/08/\$25.00 C2008 IEEE, Hal 48214824

Manunggal, 2005, Perancangan dan Pembuatan Perangkat Lunak Pengenalan Suara Pembicara dengan Menggunakan Analisa MFCC Feature Extraction. Surabaya : Universitas Kristen Petra, Hal 1-33.

Mertens, R., Huang, P., Gottlieb, L., Friedland, G. dan Divakaran, A., 2011,On the Applicability of Speaker Diarization to Audio Concept Detection for Multimedia Retrieval, 2011 IEEE International Symposium on Multimedia, IEE Computer Society, Hal 446-451 
Mustofa, A., 2007, Sistem Pengenalan Penutur dengan Metode Mel-frequency Wrapping, Jurnal Teknik Elektro Vol. 7, No. 2, September 2007: Hal 88 - 96

Silberschatz, Korth dan Sudarshan, 2011, Databases Systems Concept, $5^{\text {th }}$ ed, McGrawHill, Hal 1-31

Suyanto dan Putro, A.E., 2014, Automatic Segmentation of Indonesian Speech into Syllabes using Fuzzy Smoothed Energy Contour with Local Normalization, Splitting, and Assimilation, J.ICT Res.Appl.,Vol.8 No.2. 2014, Hal 97-112

Suyanto dan Hartati, S., 2013, Design of Indonesian LVCSR Using Combined Phoneme and Syllable Models, The Proceedings of The $7^{\text {th }}$ ICTS, Bali May 15-16 2013, Hal $191-$ 196 